\title{
Risk factors of postoperative pulmonary complications in patients with asthma and COPD
}

Takanori Numata* (1D, Katsutoshi Nakayama, Satoko Fujii, Yoko Yumino, Nayuta Saito, Masahiro Yoshida, Yusuke Kurita, Kenji Kobayashi, Saburo Ito, Hirofumi Utsumi, Haruhiko Yanagisawa, Mitsuo Hashimoto, Hiroshi Wakui, Shunsuke Minagawa, Takeo Ishikawa, Hiromichi Hara, Jun Araya, Yumi Kaneko and Kazuyoshi Kuwano

\begin{abstract}
Background: Postoperative pulmonary complications (PPC) in patients with pulmonary diseases remain to be resolved clinical issue. However, most evidence regarding PPC has been established more than 10 years ago. Therefore, it is necessary to evaluate perioperative management using new inhalant drugs in patients with obstructive pulmonary diseases.

Methods: April 2014 through March 2015, 346 adult patients with pulmonary diseases (257 asthma, 89 chronic obstructive pulmonary disease (COPD)) underwent non-pulmonary surgery except cataract surgery in our university hospital. To analyze the risk factors for PPC, we retrospectively evaluated physiological backgrounds, surgical factors and perioperative specific treatment for asthma and COPD.

Results: Finally, 29 patients with pulmonary diseases (22 asthma, 7 COPD) had PPC. In patients with asthma, smoking index ( $\geq 20$ pack-years), peripheral blood eosinophil count $\left(\geq 200 / \mathrm{mm}^{3}\right.$ ) and severity (Global INitiative for Asthma(GINA) STEP $\geq 3$ ) were significantly associated with PPC in the multivariate logistic regression analysis [odds ratio $(95 \%$ confidence interval) $=5.4(1.4-20.8), 0.31(0.11-0.84)$ and $3.2(1.04-9.9)$, respectively]. In patients with COPD, age, introducing treatment for COPD, upper abdominal surgery and operation time ( $\geq 5 \mathrm{~h}$ ) were significantly associated with PPC [1.18 (1.00-1.40), 0.09 (0.01-0.81), 21.2 (1.3-349) and 9.5 (1.2-77.4), respectively].

Conclusions: History of smoking or severe asthma is a risk factor of PPC in patients with asthma, and age, upper abdominal surgery, or long operation time is a risk factor of PPC in patients with COPD. Adequate inhaled corticosteroids treatment in patients with eosinophilic asthma and introducing treatment for COPD in patients with COPD could reduce PPCs.
\end{abstract}

Keywords: Risk factors, Postoperative pulmonary complication, Asthma, COPD, Eosinophils

\section{Background}

Postoperative pulmonary complications (PPCs) and their management are clinically important in patients with asthma and chronic obstructive pulmonary disease (COPD). PPCs include bronchospasm, atelectasis, pulmonary infection, respiratory failure and exacerbation of chronic pulmonary disease [1]. The prevalence of PPCs

\footnotetext{
*Correspondence: t-numata@jikei.ac.jp

Division of Respiratory Diseases, Department of Internal Medicine, Jikei University School of Medicine, 3-25-8, Nishi-Shimbashi, Minato-ku, Tokyo, Japan
}

(c) The Author(s). 2018 Open Access This article is distributed under the terms of the Creative Commons Attribution 4.0 International License (http://creativecommons.org/licenses/by/4.0/), which permits unrestricted use, distribution, and reproduction in any medium, provided you give appropriate credit to the original author(s) and the source, provide a link to the Creative Commons license, and indicate if changes were made. The Creative Commons Public Domain Dedication waiver (http://creativecommons.org/publicdomain/zero/1.0/) applies to the data made available in this article, unless otherwise stated. PPCs contribute to mortality and longer stays in the hospital [3], it is necessary to appropriately evaluate relevant risk factors and establish perioperative management strategies. There are two types of risk factors for PPCs. One is patient-related risk factors, such as aging and pulmonary function, and the other is procedurerelated risk factors, such as anesthetic techniques and operating time [1].

Although Global INitiative for Asthma (GINA) [4] and Global initiative for chronic Obstructive Lung Diseases 
(GOLD) [5] documents describe the perioperative management, most of the evidence presented in these documents was reported from 1990 to 2000. More recent progress in treatments for pulmonary diseases, especially new inhalants and devices, has significantly improved patient quality of life. It has been reported that some video-associated surgeries could decrease the prevalence of postoperative complications [6, 7].

To reduce PPC, we implemented the preoperative pulmonary management program in our hospital over 10 years ago. In our management program, all surgical patients with an abnormal pulmonary function test undergo a medical examination performed by pulmonologists and are administered medical treatment and evaluated for risk factors for PPC development. However, most evidence regarding the risk factors for PPC was established more than 10 years ago, and recent advances in inhalant drugs have changed the clinical course in affected patients, especially those with asthma and COPD. It is therefore critically important to precisely evaluate the risk factors for PPC development during perioperative management and to use recently available inhalant drugs in patients with both asthma and COPD.

\section{Methods}

\section{Definition of asthma}

All patients with asthma were diagnosed by physicians or self-reported, when the patients had past medical histories of asthma, typical symptoms (cough, wheezing, circadian variation and seasonal episodes) and pulmonary function compatible with asthma. Severity at baseline and during exacerbation was defined according to the GINA document [4]. Recently, a category called asthmaCOPD overlap (ACO) was proposed. However, the definition of ACO has not yet been confirmed. Furthermore, patients with asthma, including those potentially in the ACO category, are at high risk of intraoperative asthma attacks, and they therefore receive inhaled or systemic corticosteroid therapy to prevent bronchospasm as a serious PPC of asthma. Therefore, in the present study, we classified asthma patients with any smoking history, including ACO, as the asthma group.

\section{Definition of COPD}

All patients were diagnosed with COPD by the physicians, based on a smoking history (smoking index $>10$ packyears), post-bronchodilator forced expiratory volume in one second $\left[\left(\mathrm{FEV}_{1}\right) /\right.$ forced volume capacity $\left.(\mathrm{FVC})\right]<0.7$ and the exclusion of other diseases [5].

\section{Study subjects}

Between April 2014 and March 2015, a total of 14,194 surgeries were performed in Jikei University hospital (Tokyo, Japan). We excluded 3782 cases of cataract surgery, 1081 pediatric surgeries (under 15 years old) and 223 cases of lung resection surgery from these cases. We excluded cataract surgery because of very short operation time, and also, we excluded lung resection surgery, because of a crucial risk factor for PPC by itself. The criteria for preoperative consultation by pulmonologists were as follows: (1) patients with any past or present pulmonary diseases, (2) patients with an abnormal pulmonary function test (spirometry) prior to general anesthesia, or (3) patients with abnormal chest images. After preoperative examinations, 421 patients met one or more of these criteria. The participants in the present study included 346 adult patients who consulted pulmonologists for asthma or COPD (Fig. 1). Patients with other pulmonary diseases were excluded from this study. Therefore, the operations covered in this study included those performed in the head, neck, limbs, abdomen, pelvis and cardiovascular system. This study was approved by the Ethical Committee of Jikei University (28-260(8503)).

\section{Data collection}

We retrospectively examined the gender, age, underlying pulmonary diseases, medication, smoking index, peripheral blood eosinophil counts, pulmonary function test (volume capacity $(\mathrm{VC})$, forced expiratory volume in one second $\left(\mathrm{FEV}_{1}\right), \mathrm{FEV}_{1} / \mathrm{FVC}$, and $\left.\% \mathrm{FEV}_{1}\right)$, Asthma Control Test (ACT), surgery-related factors (anesthetic technique, American Society of Anesthesiologists (ASA) physical status (PS), duration of operation time, and surgery site) and PPCs of all included patients. We defined PPC as bronchospasm, pneumonia, atelectasis, respiratory failure with oxygen therapy, and exacerbation of chronic pulmonary diseases within the first seven postoperative days $[1,8,9]$. We defined bronchospasm as symptoms (wheezing, shortness of breath, and cough) requiring additional medications, and we defined respiratory failure as hypoxia requiring more than oxygen therapy or prolonged oxygen therapy. We reviewed all medical records to measure these outcomes.

\section{Intervention}

Patients consulted a pulmonologist four weeks before surgery. All smokers among the included patients were instructed to quit smoking. Our standard baseline therapy for bronchial asthma is based on the GINA stepwise approach [4]. We primarily targeted safe surgeries and referred to this document. To prevent perioperative bronchospasm, we increased the dose of inhaled corticosteroids(ICS) administered to most patients. After the first visit to our department, patients with severe/uncontrolled asthma revisited the department for a final decision regarding whether surgery was advisable. In patients with GINA $\operatorname{STEP} \geq 3$, 


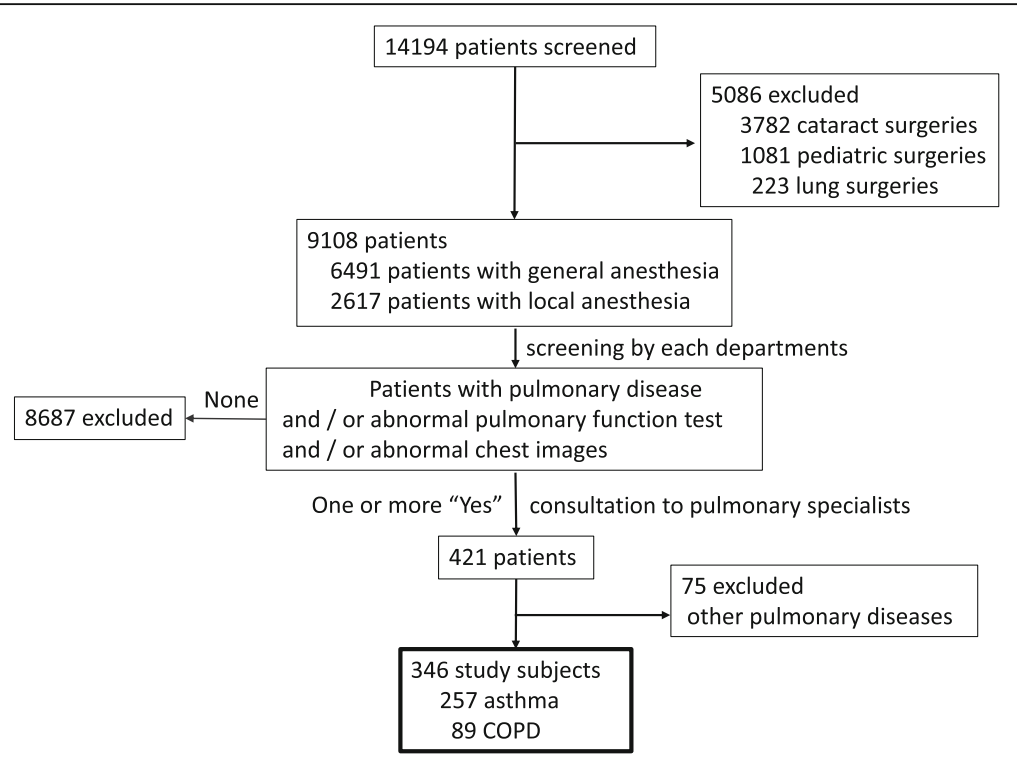

Fig. 1 Study flow

neurosurgery, emergency surgery, PPC history, or low ACT scores (approximately <22) after ICS dose escalation, we introduced systemic corticosteroids, such as prednisolone (e.g., $20 \mathrm{mg} /$ day, p.o.) for several days before surgery and a short-acting corticosteroid, such as hydrocortisone (e.g., $100 \mathrm{mg}$ i.v. every $8 \mathrm{~h}$ ) on the day of the surgery [10]. We recommended postponing the scheduled surgery in patients who had asthma exacerbation within two months. In patients with COPD, we introduced a long-acting muscarinic antagonist (LAMA), a longacting beta 2 agonist (LABA) and a combination of ICS/ LABA in accordance with the GOLD document [5]. Furthermore, in patients with very low pulmonary function, we recommended local anesthesia when possible.

\section{Statistical analysis}

All statistical analyses were performed using StatView version 5 (SAS Institute Inc., Cary, NC, USA). All values are expressed as the mean \pm standard deviation (SD). A $p$-value of $<0.05$ was considered statistically significant. The factors associated with patient characteristics were examined using a Mann-Whitney $U$ test, Student's $t$ test, Fisher's exact test, or chisquared test (univariate model). Then, a logistic regression analysis was performed to evaluate the identified PPC risk factors (multivariate model), including age, gender (male), and other variables that achieved $p<0.20$ in the univariate models. In patients with asthma, we selected age, gender (male), smoking index $(\geq 20)$, peripheral blood eosinophil count $(\geq 200 /$ $\left.\mathrm{mm}^{3}\right)$, GINA STEP $(\geq 3), \% \mathrm{FEV}_{1}$, upper abdominal surgery, perioperative systemic steroid therapy and operation time (minutes) for the multivariate analysis.
On the other hand, in patients with COPD, we selected age, gender (male), COPD treatment, upper abdominal surgery and operation time $(\geq 5 \mathrm{~h})$ for the multivariate analysis.

\section{Results}

Of the 421 patients who consulted pulmonologists for perioperative management, 257 had asthma and 89 had COPD. These patients included 186 males and 160 females. The mean age was 58.1 years old (range, 2089 years old). The remaining 75 patients who met the consultation criteria had conditions including interstitial pneumonia, bronchiectasis, pulmonary infection, and malignant diseases.

We recommended changing the anesthetic to local anesthesia in 5 patients, because these patients had exacerbated chronic respiratory diseases or very low pulmonary functions. Furthermore, we recommended cancelling 19 surgeries, which were excluded from the analysis.

\section{Medical departments/services}

A list of medical departments or services that performed surgical operations is provided in Table 1. Otolaryngology surgeries were the most frequent (177 patients) and 146 (82\%) of these patients suffered from bronchial asthma.

Patients' characteristics associated with asthma and COPD Patient characteristics associated with asthma and COPD are shown in Table 2. The mean age of the patients was younger in those with asthma than those with COPD. The mean $\mathrm{FEV}_{1} / \mathrm{FVC}$ was higher in the patients with asthma was than in the patients with COPD. In patients with asthma, disease severity at baseline was significantly 
Table 1 Medical departments that underwent surgical operations $(n=346)$

\begin{tabular}{llll}
\hline Department & male & female & total \\
\hline Otolaryngologic surgery & 98 & 79 & $177(51)$ \\
Orthopedic surgery & 19 & 18 & $37(11)$ \\
Gastrointestinal surgery & 23 & 10 & $33(9.5)$ \\
Urological surgery & 22 & 7 & $29(8.4)$ \\
Gynecological surgery & 0 & 27 & $27(7.8)$ \\
Hepatic surgery & 7 & 4 & $11(3.2)$ \\
Vascular surgery & 6 & 3 & $9(2.6)$ \\
Neurosurgery & 4 & 5 & $9(2.6)$ \\
Plastic surgery & 5 & 3 & $8(2.3)$ \\
Dermatological surgery & 1 & 2 & $3(0.9)$ \\
Breast surgery & 0 & 2 & $2(0.6)$ \\
Cardiac surgery & 1 & 0 & $1(0.3)$ \\
\hline
\end{tabular}

Data are presented as $n, n$ (\%)

associated with perioperative systemic corticosteroids treatment, and patients with severer asthma were treated with systemic corticosteroids $(p<0.0001$, chi-square test, data not shown). A symptom questionnaire was performed at enrolment and completed by $77 \%$ of patients with asthma. The results revealed that there was a significant difference in ACT scores according to the GINA STEP ( $<<0.0001$, chi-square test, Table 3). Furthermore, there was a significant difference in ACT scores between the groups with and without perioperative corticosteroid treatment $(22.3 \pm 3.5 \quad(n=106)$ and $23.2 \pm 2.2 \quad(n=92)$, respectively, $p=0.023$, Student's $t$ test, data not shown).

\section{Postoperative pulmonary complications}

In our study, 29 of 346 patients with asthma or COPD had PPCs. The details related to the PPCs and the

Table 2 Clinical characteristics in asthma and COPD patients

\begin{tabular}{lll}
\hline & asthma $(n=257)$ & $\operatorname{COPD}(n=89)$ \\
\hline gender, male / female & $111 / 146$ & $75 / 14$ \\
age, years(range) & $53.8 \pm 16.0(20-88)$ & $70.6 \pm 8.3(49-89)$ \\
BMl, kg/m ${ }^{2}$ & $23.3 \pm 4.5$ & $23.0 \pm 23.0$ \\
Smoking index, pack-years & $9.4 \pm 16.7$ & $47.7 \pm 33.6$ \\
(never/former/current) & $(130 / 104 / 23)$ & $(3 / 61 / 25)$ \\
\%VC, \% & $110.5 \pm 18.2$ & $104.1 \pm 20.5$ \\
FEV 1 /FVC, \% & $70.5 \pm 12.2$ & $59.3 \pm 7.7$ \\
\%FEV $1, \%$ & $91.7 \pm 19.6$ & $84.5 \pm 21.1$ \\
GINA STEP, 1/2/3/4/5 & $67 / 58 / 94 / 34 / 4$ & $\mathrm{NA}$ \\
CS (+), $\mathrm{n}_{1} / \mathrm{n}_{2} / \mathrm{n}_{3} / \mathrm{n}_{4} / \mathrm{n}_{5}$ & $25 / 19 / 60 / 25 / 4$ & $\mathrm{NA}$ \\
GOLD stage, 1/2/3/4 & $\mathrm{NA}$ & $47 / 35 / 6 / 1$
\end{tabular}

Data are presented as $\mathrm{n}$ or mean $\pm \mathrm{SD}$ (range)

$N A$ not available

CS systemic corticosteroids

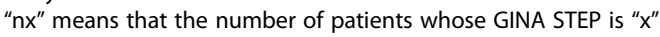

clinical characteristics of the patients with asthma and COPD are shown in Tables 4, 5 and 6, respectively. Of the 257 patients with asthma, 18 (7.0\%) had the PPC mild/moderate bronchospasm, and their symptoms promptly improved with additional treatment. There was a significant difference in ACT scores between the groups with and without PPCs $(21.2 \pm 4.8 \quad(n=16)$ vs $22.9 \pm 2.8(n=182)$, respectively; $p=0.032$, Student's $t$ test, data not shown).

Of the 89 patients with COPD, seven (7.9\%) had PPCs, mainly pneumonia accompanied by respiratory failure. The hospitalization period was extended in these patients, but all of them survived. Nineteen of the patients underwent surgery with local anesthesia, including three in whom general was changed to local anesthesia. Of these 19 patients, no one had a PPC, but there was no difference in the prevalence of PPCs between patients treated with general and local anesthesia ( $p=0.39$, Fisher's exact test). There was no significant difference in the prevalence of PPCs between patients who underwent laparoscopic surgery and those who did not ( $p=0.94$, chi-square test).

\section{Risk factors}

We performed a univariate analysis to assess PPC risk factors in asthma (Table 5) and COPD (Table 6) patients. Regarding procedure-related risk factors in the univariate analysis, a longer operation time was a risk factor for PPCs. However, laparoscopic surgery did not decrease the prevalence of PPCs in the present study. We then evaluated PPC risk factors in a multivariate logistic regression analysis using the extracted variables shown in Table 7. Accordingly, the following were PPC risk factors in asthma patients: smoking history $\geq 20$ packyears [odds ratio (OR) 5.4, 95\% confidence interval (CI) (1.4-20.8), $p=0.014$ ], peripheral blood eosinophil count $\geq 200 / \mathrm{mm}^{3}$ [0.31, $\left.(0.11-0.84), p=0.021\right]$, GINA STEP $\geq 3$ [3.2, (1.04-9.9), $p=0.043]$. However, there was no significant difference between former and current smokers in the incidence of PPCs in the univariate analysis ( $p=0.28$, Fisher's exact test, data not shown).

The following PPC risk factors associated with COPD were identified in the multivariate logistic regression analysis: age [1.18, $(1.00-1.40), p=0.046]$, the introduction of COPD treatment $[0.09,(0.01-0.81), p=0.032]$, upper abdominal surgery [21.2, (1.3-349), $p=0.033]$, and an operation time $\geq 5 \mathrm{~h}[9.5,(1.2-77.4), p=0.035]$ (Table 7).

\section{Discussion}

In the present study, we show that treating asthma with perioperative systemic corticosteroids seemed to significantly increase the risk of PPCs in the univariate analysis. However, no significant risk of PPCs was detected for systemic corticosteroids in the multivariate logistic 
Table 3 ACT scores and GINA STEP

\begin{tabular}{lllllll}
\hline GINA STEP $(n=257)$ & $1(n=67)$ & $2(n=58)$ & $3(n=94)$ & $4(n=34)$ & $5(n=4)$ & $p$ value \\
\hline ACT score $(n=198)$ & $24.5 \pm 1.0(n=45)$ & $23.3 \pm 1.9(n=43)$ & $22.0 \pm 3.0(n=81)$ & $21.2 \pm 4.5(n=25)$ & $20.3 \pm 5.5(n=4)$ & $<0.0001^{*}$ \\
\hline $\begin{array}{l}\text { Data are presented as } n \text { or mean } \pm \text { SD } \\
\text { * }\end{array}$
\end{tabular}

*chi-square test

analysis. Does treatment with systemic corticosteroids increase the risk of PPCs? Previous studies reported that the incidence of PPCs in untreated patients with asthma was $24 \%$ [11], whereas it was $4.5 \%$ in patients with asthma who received perioperative systemic corticosteroids [12]. In the present study, the incidence of bronchospasm in patients with treated asthma was 7.0\%, similar to the results observed in later studies. As described in the methods and the results section, all of the patients with asthma were treated with ICS, and some with more severe and unstable asthma were also treated with systemic corticosteroids. The patients with severe/uncontrolled asthma were more likely to experience PPC events. Accordingly, treatment with systemic corticosteroids behaved like a risk factor in the univariate analysis. However, in the multivariate analysis of factors associated with disease severity, this potential disadvantage was cancelled out. The results of our study suggest that increasing the ICS dose is sufficient to prevent bronchospasm in patients with mild and stable asthma. Because most of bronchospasms that present as PPCs are mild, we propose that in clinical practice, systemic corticosteroids effectively minimize the severity of PPCs in patients with severe asthma.

According to the multivariate logistic analysis of patients with asthma, peripheral blood eosinophilia and a history of heavy smoking were significantly associated with PPCs. Both of these variables are implicated in steroid responsiveness. Interestingly, the result of the present study demonstrated that a peripheral blood eosinophil count $\geq 200 / \mathrm{mm}^{3}$ decreased the risk of PPCs to one-third. There are several phenotypes of bronchial asthma [13]. The eosinophilic asthma phenotype that presents with a higher eosinophil count in the blood and sputum responded better to inhaled or systemic

Table 4 Details of postoperative pulmonary complications

\begin{tabular}{lll}
\hline PPC & $\begin{array}{l}\text { asthma patients } \\
(n=257)\end{array}$ & $\begin{array}{l}\text { COPD patients } \\
(n=89)\end{array}$ \\
\hline Total patients with PPC & $22(8.6)$ & $7(7.9)$ \\
Bronchospasm & $18(7.0)$ & $0(0.0)$ \\
Pneumonia/atelectasis $^{\text {Respiratory failure }}$ & $4(1.6)$ & $7(7.9)$ \\
Re $^{\mathrm{a}}$ & $2^{\mathrm{b}}(0.8)$ & $1^{\mathrm{b}}(1.1)$ \\
\hline
\end{tabular}

Data are presented as $\mathrm{n}(\%)$

${ }^{a}$ All patients complicated with respiratory failure had pneumonia and/or atelectasis

${ }^{\mathrm{b}}$ One patient in each group required mechanical ventilation corticosteroid therapy [14-16]. Hence, perioperative intervention could effectively reduce PPC risk in eosinophilic asthma. We also found that a blood eosinophil count of approximately $200 / \mathrm{mm}^{3}$ was correlated with both sputum eosinophil count and the efficacy of ICS $[14,16,17]$. Our result is compatible with those reported in other studies.

A smoking history of $\geq 20$ pack-years was associated a five-fold increased risk of PPCs. However, Chaudhuri et al. [18] demonstrated that the efficacy of treatment with oral corticosteroids was impaired even in former smokers with asthma. Colak et al. [19] also found that in patients with asthma, the risk of exacerbations and pneumonia was higher in current/former smokers vs never smokers, perhaps because the efficacy of inhaled corticosteroids is reduced by smoking. The reason for this phenomenon could be that cigarette smoking inactivated histone deacetylase activity, which is important for the corticosteroidmediated repression of anti-inflammatory gene expression [20]. Therefore, smoking could be an important PPC risk factor, even in patients with asthma who receive appropriate treatments. Again, eosinophilia and a history of heavy smoking are associated with sensitivity and resistance, respectively, to corticosteroids, and both are therefore related to steroid responsiveness in a broad sense. Hence, in the present study, steroid responsiveness was viewed as a crucial factor that influenced PPC risks.

Patients with ACO were included in the asthma group in the present study. There were three reasons for this. First, no standardized definition has yet been established for ACO. Recently, a new definition, including a post-bronchodilator $\mathrm{FEV}_{1} / \mathrm{FVC}<0.7$ and a peripheral blood eosinophil count $>400 / \mathrm{mm}^{3}$, was proposed [21] that requires verification. Second, patients with $\mathrm{ACO}$ are more responsive to corticosteroids than are patients with COPD alone [22]. Because inhaled and systemic corticosteroids are required to treat bronchospasm and wheezing, symptoms that are caused by eosinophilic airway inflammation, we emphasized this fact. The latest GINA document recommends starting treatment for asthma in affected patients [23]. Third, asthma patients with a smoking history and irreversible air flow obstruction, including patients with ACO, were treated with ICS/LABA therapy to prevent bronchospasm, which was the most considerable complication of asthma. We therefore included the patients with ACO 
Table 5 Clinical characteristics of asthma patients with PPCs (+) or (-)

\begin{tabular}{|c|c|c|c|}
\hline Variables & $\operatorname{PPC}(+) n=22$ & $\mathrm{PPC}(-) n=235$ & $p$-value \\
\hline gender, male/female & $10 / 12$ & $101 / 134$ & $0.82^{*}$ \\
\hline age, years & $56.5 \pm 15.4$ & $53.5 \pm 16.1$ & $0.43^{+}$ \\
\hline $\mathrm{BMI}, \mathrm{kg} / \mathrm{m}^{2}$ & $23.1 \pm 3.0$ & $23.3 \pm 4.7$ & $0.95^{\dagger}$ \\
\hline $\begin{array}{l}\text { Smoking Index, } \\
\text { pack-years }\end{array}$ & $18.3 \pm 23.8$ & $8.6 \pm 15.9$ & $0.15^{\dagger}$ \\
\hline$\% \vee C, \%$ & $107.8 \pm 22.1$ & $110.7 \pm 17.8$ & $0.61^{\dagger}$ \\
\hline$\% \mathrm{FEV}_{1}, \%$ & $96.5 \pm 22.8$ & $91.3 \pm 19.3$ & $0.15^{\dagger}$ \\
\hline $\begin{array}{l}\text { Peripheral blood } \\
\text { eosinophil, /mm³ }\end{array}$ & $245 \pm 183$ & $337 \pm 271$ & $0.085^{\dagger}$ \\
\hline GINA STEP $\geq 3, y / n$ & $16 / 6$ & $116 / 119$ & $0.061^{*}$ \\
\hline $\begin{array}{l}\text { Perioperative CS } \\
(+), y / n\end{array}$ & $17 / 5$ & $116 / 119$ & $0.022^{*}$ \\
\hline ASA-PS, 1/2/3- & $1 / 19 / 2$ & $13 / 201 / 19$ & $0.97^{*}$ \\
\hline $\begin{array}{l}\text { Upper abdominal } \\
\text { surgery, y/n }\end{array}$ & $4 / 18$ & $15 / 220$ & $0.11^{\ddagger}$ \\
\hline $\begin{array}{l}\text { Laparoscopic } \\
\text { surgery, y/n }\end{array}$ & $4 / 18$ & $32 / 203$ & $0.52^{\ddagger}$ \\
\hline $\begin{array}{l}\text { Operation time, } \\
\text { min }\end{array}$ & $200 \pm 150$ & $141 \pm 86$ & $0.023^{\dagger}$ \\
\hline
\end{tabular}

Data are presented as $n$ or mean $\pm S D$, unless otherwise stated

CS systemic corticosteroids

ASA-PS American Society of Anesthesiologists physical status

${ }^{*}$ chi-square test, ${ }^{\dagger}$ Mann-Whitney $U$ test, ${ }^{\neq}$Fisher's exact test

Table 6 Clinical characteristics of COPD patients with PPCs (+) or (-)

\begin{tabular}{|c|c|c|c|}
\hline Variables & $\mathrm{PPC}(+) n=7$ & $\operatorname{PPC}(-) n=82$ & $p$-value \\
\hline gender, male / female & $7 / 0$ & $68 / 14$ & $0.59^{\ddagger}$ \\
\hline age, years & $77.3 \pm 7.9$ & $70.0 \pm 8.1$ & $0.034^{+}$ \\
\hline $\mathrm{BMI}, \mathrm{kg} / \mathrm{m}^{2}$ & $23.8 \pm 2.6$ & $23.0 \pm 3.0$ & $0.66^{+}$ \\
\hline Smoking Index, pack-years & $40.7 \pm 8.6$ & $48.2 \pm 34.7$ & $0.88^{\dagger}$ \\
\hline$\% \vee C, \%$ & $104.8 \pm 15.5$ & $104.0 \pm 21.0$ & $0.99^{\dagger}$ \\
\hline$\% \mathrm{FEV}_{1}, \%$ & $89.5 \pm 11.0$ & $84.1 \pm 21.7$ & $0.34^{+}$ \\
\hline GOLD stage (1/2/3/4) & $6 / 1 / 0 / 0$ & $41 / 34 / 6 / 1$ & $0.39^{*}$ \\
\hline $\begin{array}{l}\text { Peripheral blood } \\
\text { eosinophil, /mm³ }\end{array}$ & $210 \pm 97$ & $187 \pm 135$ & $0.38^{\dagger}$ \\
\hline $\begin{array}{l}\text { COPD treatment, } \\
y / n\end{array}$ & $3 / 4$ & $63 / 19$ & $0.07^{\ddagger}$ \\
\hline ASA-PS, 1/2/3- & $1 / 5 / 1$ & $7 / 62 / 13$ & $0.88^{*}$ \\
\hline $\begin{array}{l}\text { Upper abdominal } \\
\text { surgery, y/n }\end{array}$ & $2 / 5$ & $5 / 75$ & $0.14^{\ddagger}$ \\
\hline $\begin{array}{l}\text { Laparoscopic } \\
\text { surgery, y/n }\end{array}$ & $1 / 6$ & $15 / 67$ & $>0.99^{\ddagger}$ \\
\hline Operation time, min & $393 \pm 149$ & $196 \pm 131$ & $0.002^{\dagger}$ \\
\hline
\end{tabular}

Data are presented as $\mathrm{n}$ or mean $\pm \mathrm{SD}$, unless otherwise stated

${ }^{*}$ chi-square test, ${ }^{\dagger}$ Mann-Whitney $U$ test, ${ }^{*}$ Fisher's exact test

ASA-PS American Society of Anesthesiologists physical status 
Table 7 Risk factors of PPCs in asthma and COPD patients

\begin{tabular}{llll}
\hline & Variables & OR(95\%Cl) & $p$-value \\
\hline asthma & $\begin{array}{l}\text { Smoking index } \geq 20 \\
\text { pack-years }\end{array}$ & $5.4(1.4-20.8)$ & 0.014 \\
& Eosinophil $\geq 200 / \mathrm{mm}^{3}$ & $0.31(0.11-0.84)$ & 0.021 \\
& GINA STEP $\geq 3$ & $3.2(1.04-9.9)$ & 0.043 \\
COPD & age, years & $1.18(1.00-1.40)$ & 0.046 \\
& COPD treatments, yes & $0.09(0.01-0.81)$ & 0.032 \\
& Upper abdominal & $21.2(1.3-349)$ & 0.033 \\
& surgery, yes & & \\
& Operation time $\geq 5 \mathrm{~h}$ & $9.5(1.2-77.4)$ & 0.035 \\
\hline
\end{tabular}

These data were analyzed by multivariate logistic regression test

in the asthma group in our analysis of risk factors for PPC. It will be important to perform comparisons among these three types of obstructive pulmonary disease (bronchial asthma, ACO and COPD) in the future after a consensus is reached regarding the definition of ACO.

Next, regarding patients with COPD, previous studies have found that aging, upper abdominal surgery and operation time are risk factors for PPCs $[1,8]$. Canet et al. [24] found that an operation time longer than $2 \mathrm{~h}$ was a predictor of PPCs, and in the present study, a multivariate analysis showed that an operation time longer than $5 \mathrm{~h}$ was a risk factor of PPCs. Hence, the threshold at which operation time increases the risk of PPCs was longer. The reason for this difference might be that perioperative management and anesthetic techniques have progressed over the last decade. In particular, non-invasive ventilation and high-flow therapy are effective in preventing postextubation respiratory failure and reintubation in some patients [25-29]. To determinate whether the progress made in recent years has reduce the risk of PPCs was one of the purposes of this study. Laparoscopic surgery was not found to reduce PPC risk. We found that operation times were significantly longer in patients with COPD who underwent laparoscopic surgery than in those who underwent non-laparoscopic surgery $(288 \pm 139 \mathrm{~min}$ vs $195 \pm 141 \mathrm{~min}, p<0.01$, Mann-Whitney $U$ test, data not shown). The merit of using laparoscopic surgery to reduce the risk of PPC was masked by its intrinsically longer operation time. In addition to these risk factors, in the present study, we provide the newly evidence demonstrating that introducing treatment for COPD, including LAMA and LABA, reduced the risk of PPC. These inhaled drugs were recently developed and are much more effective in preventing COPD exacerbation. The mechanisms underlying their actions involve their ability to decrease hyperinflation and mechanical stress, to modulate mucus production and mucociliary clearance and to improve symptoms [30]. Low pulmonary function was not identified as a risk factor in this study. We changed the anesthetic techniques from general to local or cancelled the surgery in patients with advanced low pulmonary function. These adjustments reduced the risk of PPC in patients with low pulmonary function, but the difference was not significant.

\section{Limitations}

The present study has some limitations. First, this study is a retrospective case-control study performed at a single institution. Because early reports have demonstrated that systemic corticosteroid is effective as a precaution against PPC in patients with asthma, we believe that it may not be ethical to perform a prospective study using a control group consisting of untreated patients. The number of patients with asthma or COPD analyzed in the present study may depend on the proportion of surgical cases per department. Otolaryngology patients comprised approximately $20 \%$ of all patients treated with general anesthesia, and these patients often had asthma. However, the number of cases in which cardiovascular diseases, esophageal cancer or laryngopharyngeal cancer coexisted with COPD was small. Hence, multicenter cohort studies are desirable for collecting balanced data.

Second, although the total number of patients was 346 , it would be preferable to register more patients. In addition, fewer PPC events in patients with COPD were observed than expected in this study. However, the reason for the small number of PPC events could be that we managed our patients in a manner aimed at reducing PPCs. Third, we excluded patients who underwent lung resection, because it is a direct risk factor for pulmonary complications. In the future, these concerns should be addressed in separate studies.

\section{Conclusions}

In summary, our results demonstrate that asthma patients with a history of smoking or severe asthma had an increased risk of PPCs. Sufficiently and aggressively increasing ICS can reduce the risk of PPCs in asthma patients with eosinophilia. Although aging, upper abdominal surgery and long operation times are risk factors for pneumonia and respiratory failure in COPD patients, introducing treatment for COPD significantly reduces the risk of PPC by improving pulmonary function.

\footnotetext{
Abbreviations

ACO: Asthma-COPD overlap; ACT: Asthma Control Test; ASA-PS: American Society of Anesthesiologists physical status; Cl: Confidence interval; COPD: Chronic obstructive pulmonary disease; $\mathrm{FEV}_{1}$ : Forced expiratory volume in one second; FVC: Forced volume capacity; GINA: Global Initiative for Asthma; GOLD: Global initiative for chronic Obstructive Lung Diseases; ICS: Inhaled corticosteroids; LABA: Long-acting beta 2 agonist; LAMA: Longacting muscarinic antagonist; OR: Odds ratio; PPC: Postoperative pulmonary complication; SD: Standard deviation; VC: Volume capacity
}

\section{Funding}

None 


\section{Availability of data and materials}

The datasets used and/or analyzed during the current study are available from the corresponding author on reasonable request.

\section{Authors' contributions}

Concept and design: TN, SF, YY, data interpretation, writing of manuscript, revision of manuscript: TN, KN, SF, YY, HH, JA, Data Analysis and interpretation: TN, KN, Original data collection and revision of manuscript: TN, NS, MY, HU, HY, MH, KK, YK, SI, HW, SM, TI. KN and KK assisted in the writing of the manuscript and provided helpful discussion. All authors read and approved the final manuscript.

\section{Ethics approval and consent to participate}

In the retrospective study, written informed consent from the participants involved was unavailable and unnecessary.

The Ethical Committee of Jikei University School of Medicine approved that patient consent was not necessary for this retrospective study (28260(8503)). Instead, this study was posted on a bulletin board in this hospital.

\section{Consent for publication}

Not applicable.

\section{Competing interests}

The authors declare that they have no competing interests.

\section{Publisher's Note}

Springer Nature remains neutral with regard to jurisdictional claims in published maps and institutional affiliations.

Received: 23 July 2017 Accepted: 22 December 2017

\section{Published online: 09 January 2018}

\section{References}

1. Smetana GW. Preoperative pulmonary evaluation. N Engl J Med. 1999; 340:937-44.

2. Kroenke K, Lawrence VA, Theroux JF, Tuley MR, Hilsenbeck S. Postoperative complications after thoracic and major abdominal surgery in patients with and without obstructive lung disease. Chest. 1993;104:1445-51.

3. Smetana GW, Lawrence VA, Cornell JE. Preoperative pulmonary risk stratification for noncardiothoracic surgery: systematic review for the American College of Physicians. Ann Intern Med. 2006;144:581-95.

4. Global Initiative for Asthma. Global Strategy For Asthma Management and Prevention. revised 2014. http://www. ginasthma.org. Accessed 21 May 2014.

5. Vestbo J, Hurd SS, Agusti AG, Jones PW, Vogelmeier C, Anzueto A, Barnes PJ, Fabbri LM, Martinez FJ, Nishimura M, Stockley RA, Sin DD, Rodriguez-Roisin R. Global strategy for the diagnosis, management, and prevention of chronic obstructive pulmonary disease GOLD executive summary. Am J Respir Crit Care Med. 2013:187:347-65.

6. Swanson SJ, Meyers BF, Gunnarsson CL, Moore M, Howington JA, Maddaus MA, McKenna RJ, Miller DL. Video-assisted thoracoscopic lobectomy is less costly and morbid than open lobectomy: a retrospective multiinstitutional database analysis. Ann Thorac Surg. 2012;93:1027-32.

7. Wang J-f, Zhang S-z, Zhang N-y, Wu Z-y, Feng J-y, Ying LP, Zhang JJ. Laparoscopic gastrectomy versus open gastrectomy for elderly patients with gastric cancer : a systematic review and. World J Surg Oncol. 2016;14:90-9.

8. Qaseem A, Snow V, Fitterman N, Hornbake ER, Lawrence VA, Smetana GW, Weiss K, Owens DK, Aronson M, Barry P, Casey DE Jr, Cross JT Jr, Sherif KD, Weiss KB. Risk assessment for and strategies to reduce perioperative pulmonary complications for patients undergoing noncardiothoracic surgery: a guideline from the American College of Physicians. Ann Intern Med. 2006;144:575-80.

9. McAlister FA, Bertsch K, Man J, Bradley J, Jacka M. Incidence of and risk factors for pulmonary complications after nonthoracic surgery. Am J Respir Crit Care Med. 2005;171:514-7.

10. National Asthma Education and Prevention Program. Expert panel report 3 (EPR-3): guidelines for the diagnosis and Management of Asthma-Summary Report 2007. J Allergy Clin Immunol. 2007;120:S94-138.

11. Palmer KN. Post-operative pulmonary complications. Postgrad Med J. 1955;31:25-9.

12. Kabalin CS, Yarnold PR, Grammer LC. Low complication rate of corticosteroid-treated asthmatics undergoing surgical procedures. Arch Intern Med. 1995;155:1379-84.
13. Haldar P, Pavord ID, Shaw DE, Berry MA, Thomas M, Brightling CE, Wardlaw AJ, Green RH. Cluster analysis and clinical asthma phenotypes. Am J Respir Crit Care Med. 2008;178:218-24.

14. Green RH, Brightling CE, Woltmann G, Parker D, Wardlaw AJ, Pavord ID. Analysis of induced sputum in adults with asthma: identification of subgroup with isolated sputum neutrophilia and poor response to inhaled corticosteroids. Thorax. 2002;57:875-9.

15. Pavord ID, Brightling CE, Woltmann G, Wardlaw AJ. Non-eosinophilic cor ticosteroid unresponsive asthma. Lancet. 1999;353:2213-4.

16. Schleich FN, Manise M, Sele J, Henket M, Seidel L, Louis R. Distribution of sputum cellular phenotype in a large asthma cohort: predicting factors for eosinophilic vs neutrophilic inflammation. BMC Pulm Med. 2013;13:1-8.

17. McGrath KW, Icitovic N, Boushey HA, Lazarus SC, Sutherland ER, Chinchilli VM, Fahy JVA. Large subgroup of mild-to-moderate asthma is persistently noneosinophilic. Am J Respir Crit Care Med. 2012;185:612-9.

18. Chaudhuri R, Livingston E, McMahon AD, Thomson L, Borland W, Thomson NC. Cigarette smoking impairs the therapeutic response to oral corticosteroids in chronic asthma. Am J Respir Crit Care Med. 2003;168:1308-11.

19. Colak Y, Afzal S, Nordestgaard BG, Lange P. Characteristics and prognosis of never-smokers and smokers with asthma in the copenhagen general population study: a prospective cohort study. Am J Respir Crit Care Med. 2015:192:172-81.

20. Barnes PJ, Adcock IM, Ito K. Histone acetylation and deacetylation: importance in inflammatory lung diseases. Eur Respir J. 2005;25:552-63.

21. Miravitlles M, Alvarez-Gutierrez FJ, Calle M, Casanova C, Cosio BG, López-Viña A, Pérez de Llano L, Quirce S, Roman-Rodríguez M, SolerCataluña JJ, Plaza V. Algorithm for identification of asthma-COPD overlap: consensus between the Spanish COPD and asthma guidelines. Eur Respir J. 2017; https://doi.org/10.1183/13993003.00068-2017.

22. Sin DD, Miravitlles M, Mannino DM, Soriano JB, Price D, Celli BR, Leung JM, Nakano Y, Park HY, Wark PA, Wechsler ME. What is asthma?COPD overlap syndrome? Towards a consensus definition from a round table discussion. Eur Respir J. 2016:48:664-73.

23. Global Initiative for Asthma. Global Strategy for Asthma Management and Prevention, 2017 update. http://ginasthma.org. Accessed: 1 June 2017.

24. Canet J, Gallart L, Gomar C, Paluzie G, Vallès J, Castillo J, Sabaté S, Mazo V, Briones Z, Sanchis J, ARISCAT Group. Prediction of postoperative pulmonary complications in a population-based surgical cohort. Anesthesiology. 2010; 113:1338-50.

25. Faria DA, da Silva EM, Atallah ÁN, Vital FM. Noninvasive positive pressure ventilation for acute respiratory failure following upper abdominal surgery Cochrane Database Syst Rev. 2015; https://doi.org/10.1002/14651858. CD009134.pub2.

26. Futier E, Burtz CP, Godet T, Ear LK, Rozencwajg S, Delay JM, Verzilli D, Dupuis J, Chanques G, Bazin JE, Constantin JM, Pereira B, Jaber S. Effect of early postextubation high - flow nasal cannula vs conventional oxygen therapy on hypoxaemia in patients after major abdominal surgery: a French multicentre randomised controlled trial (OPERA). Intensive Care Med. 2016; 42:1888-98.

27. Glossop AJ, Shepherd N, Bryden DC, Mills GH. Non-invasive ventilation for weaning, avoiding reintubation after extubation and in the postoperative period: a meta-analysis. Br J Anaesth. 2012;109:305-14.

28. Hernández G, Vaquero C, González P, Subira C, Fernando Frutos-Vivar M, Rialp G, Laborda C, Colinas L, Cuena R, Fernández R. Effect of Postextubation high-flow nasal cannula vs conventional oxygen therapy on reintubation in low-risk patients a randomized clinical trial. JAMA. 2016:315:1354-61.

29. Hernández G, Vaquero C, Colinas L, Cuena R, González P, Canabal A, Sanchez S, Rodriguez ML, Villasclaras A, Fernández R. Effect of Postextubation high-flow nasal cannula vs noninvasive ventilation on reintubation and Postextubation respiratory failure in high-risk patients a randomized clinical trial. JAMA. 2016;316:1565-74.

30. Beeh KM, Burgel PR, Franssen FM, Lopez-Campos JL, Loukides S, Hurst JR, Fležar M, Ulrik CS, Di Marco F, Stolz D, Valipour A, Casserly B, Ställberg B, Kostikas K, Wedzicha JA. How do dual long-acting bronchodilators prevent exacerbations of chronic obstructive pulmonary disease? Am J Respir Crit Care Med. 2017;196:139-49. 